\title{
Título da página eletrónica: Oficina Precaria
}

URL: http://oficinaprecaria.org

José Soeiro

\section{(2) OpenEdition \\ Journals}

Edição electrónica

URL: http://journals.openedition.org/rccs/5596

DOI: $10.4000 /$ rccs.5596

ISSN: 2182-7435

\section{Editora}

Centro de Estudos Sociais da Universidade de Coimbra

\section{Edição impressa}

Data de publição: 1 maio 2014

Paginação: 217-218

ISSN: 0254-1106

Refêrencia eletrónica

José Soeiro, «Título da página eletrónica: Oficina Precaria », Revista Crítica de Ciências Sociais [Online], 103 | 2014, posto online no dia 27 maio 2014, consultado o 22 setembro 2020. URL : http:// journals.openedition.org/rccs/5596; DOI : https://doi.org/10.4000/rccs.5596 


\section{Espaço Virtual}

\section{Título da página eletrónica: Global Labour Column URL: http://column.global-labour-university.org/}

\begin{abstract}
A Global Labour Column é uma página eletrónica Global que constitui um fórum permanente de partilha de conhecimento e de experiências entre o movimento sindical e investigadores da área. Esta é parte integrante de uma rede constituída pela Organização Internacional do Trabalho (OIT), por sindicatos e universidades intitulada Global Labour University (GLU). A GLU fornece um programa de mestrados para estudantes com um percurso de envolvimento em movimentos sociais e sindicalismo de todo o mundo. Iniciado em 2004 na Alemanha, o programa de mestrado encontra-se disponível também na África do Sul, Brasil, Índia e, a partir de 2014, nos Estados Unidos da América. Existem diversos espaços virtuais onde as questões relacionadas com os desafios e as oportunidades que se colocam atualmente à ação sindical se encontram

presentes. A singularidade da Global Labour Column, juntamente com a GLU, prende-se com a filosofia subjacente à sua criação - a de não constituir um mero espaço de reflexão académica mas o de poder contribuir para reforçar a capacidade de reflexão estratégica das organizações de trabalhadores.

Os artigos publicados incluem textos de opinião, resumos de trabalhos académicos, comentários a medidas governamentais e a lutas em curso, discussões e debates sobre contextos específicos nacionais e o movimento sindical global. É possível encontrar textos em cinco línguas - espanhol, francês, inglês, português e russo. É gerida por uma das instituições parceiras da GLU, através do programa de investigação Corporate Strategy and Industrial Development (CSID) da Universidade de Witwatersrand, África do Sul.
\end{abstract}

\section{Título da página eletrónica: Global Labour Journal URL: http://digitalcommons.mcmaster.ca/globallabour/}

O Global Labour Journal é uma publicação académica, de acesso livre, submetida a avaliação por pares, lançada em janeiro de 2010. É publicada em parceria com o Comité de Investigação n. 44 (Movimentos Sindicais) da Associação Internacional de Sociologia (ISA).

Este jornal procura captar a diversidade da produção académica produzida na atualidade sobre as diversas dimensões do trabalho e dos movimentos de trabalhadores, enquanto fenómeno crescentemente moldado por forças globais mais amplas, de forma a promover a constituição de um genuíno sindicalismo global. Aceita contributos de diferentes disciplinas académicas e uma pluralidade de abordagens académicas.

O seu conselho editorial é composto por alguns dos mais destacados especialistas dos estudos sindicais à escala global. Com destaque para Andries Bezuidenhout, Peter Fairbrother, Sam Gindin, Andrew 
Herod, Robert Lambert, Ruth Milkman, Ronaldo Munck, Robert O’Brien, Gay Seidman, Dimitris Stevis, Peter Waterman e Edward Webster, entre outro/as.

Ao longo dos últimos cinco anos, o Global Labour Journal tem publicado estudos e reflexões que procuram abarcar diversas regiões do mundo, revisitando velhas temáticas e introduzindo novos e insti- gantes temas à colação. Exemplo disso é o texto publicado por Michael Burawoy (volume 1, número 2 ) sobre as virtualidades do uso de conceitos polanyianos nos Estudos Laborais Globais, o que gerou um intenso debate ao longo dos números posteriores da publicação.

Hugo Dias

\section{Título da página eletrónica: Mob URL: http://moblisboa.org}

No ano de 2012, a associação Precários Inflexíveis (PI), nascida na sequência do primeiro MayDay Lisboa, em 2007, juntava-se à cooperativa cultural Crew Hassan para abrir um novo espaço, que tomava a forma legal de uma associação: o Mob. Os PI eram então já conhecidos pelo seu ativismo na luta contra a precariedade, na denúncia de abusos laborais e na dinamização de campanhas públicas com grande visibilidade em torno de temas como os recibos verdes ou as dívidas à segurança social. A Crew Hassan, por seu turno, tinha sido criada em 2004 a partir da iniciativa de um grupo de amigos ligados às artes e à música, desenvolvendo desde então atividades de âmbito cultural e social, com um espaço na baixa de Lisboa, que incluía um bar, uma loja de comércio justo e uma área onde se realizavam múltiplas atividades, da música ao cinema, do teatro aos debates políticos.

O Mob, que funcionou até ao final de 2013 no Bairro Alto, em Lisboa, mudou-se em 2014 para o Intendente, na mesma cidade. Desta vez, o espaço passou a ser partilhado entre os Precários Inflexíveis e o coletivo pelo direito à habitação Habita, criado em 2012 por ativistas de diferentes áreas em torno da luta pela habitação e pelo direito à cidade, combate que "desafia os múltiplos processos de segregação, precarização, discriminação e expulsão das nossas cidades".

Nesta página eletrónica encontra-se a programação do Mob e é também através dela que podem propor-se iniciativas a serem ali acolhidas. O local funciona como uma espécie de centro social, "palco de cultura alternativa e bastidor de mobilizações", ponto de encontro de militantes sociais e políticos, espaço aberto à comunidade, lugar de "auto-organização e mobilização para o que faz falta”, como se escreve na apresentação que é feita na página. De entre as atividades realizadas contam-se noites temáticas, grupos de estudos, aulas de teatro, sessões de jogos de tabuleiro, workshops de escrita criativa ou de preparação física, apresentação de livros, sessões de leitura, mostras de cinema, exposições e atividades para crianças. Contam-se também, claro está, as reuniões semanais do coletivo Habita, todas as segundas-feiras ao final da tarde, as assembleias dos PI e as sessões de esclarecimento sobre direitos laborais que esta associação promove todas as sextas-feiras, entre as $19 \mathrm{~h}$ e as $20 \mathrm{~h}$.

Nos seus estudos clássicos sobre o processo de formação da classe operária, Thompson insistia na importância de o analisar a partir da experiência dos trabalhadores, 
não apenas nas relações económicas, mas na vida comunitária, nos espaços de sociabilidade e nos seus modos culturais. De facto, é no mundo do não trabalho que frequentemente as classes subalternas puderam pensar sobre a sua condição e organizar-se para revertê-la. Não é por acaso que as autoridades dos finais do século XIX, nomeadamente em Inglaterra, se empenharam em controlar e proibir as feiras e as tabernas. Elas eram focos de criação de consciência de classe e de preparação de resistência política. Também a experiência dos centros sociais teve, para o movimento autónomo dos anos 60 e 70 do século Xx, designadamente em países como Itália, uma importância fundamental na criação de espaços de cultura, politização e de organização que se subtraíam às regras da sociedade mercantil e da economia capitalista, organizando a experiência social a partir de outros princípios e lógicas.

No tempo da comunicação em rede e do ciberativismo, a net proporciona um espaço de resistência, de comunicação e de organização tanto mais relevante quanto a experiência do trabalho é marcada crescentemente pela fragmentação estatutária, pela desarticulação das antigas solidariedades e pelo despotismo patronal que impede a ação coletiva. Também a experiência relacionada com o local de habitação é frequentemente vivida a partir de processos que combinam segregação social e espacial, ausência de uma identidade forte e lógicas de relegação. Mas a relevância desse espaço virtual, como se tem verificado nos conflitos sociais emergentes neste primeiro quartel do século XXI, não anula a importância e a centralidade dos espaços físicos, antes o complementa e o hibridiza. O Mob (como outros espaços que existem em Lisboa e noutras cidades europeias, nomeadamente de raiz mais libertária) parece ser, na sua escala, uma espécie de combinação, para os tempos de hoje, deste tipo de espaços físicos que, como as tabernas ou os centros sociais, misturam resistência cultural, sociabilidades coletivas e conspiração política.

\section{Título da página eletrónica: Oficina Precaria URL: http://oficinaprecaria.org}

Apresentada oficialmente no dia 1 de maio de 2012, a Oficina Precaria é um coletivo espanhol que nasce da dinâmica do movimento dos Indignados, em particular da Acampada de Madrid e de uma das organizações que a impulsionou, o Juventud Sin Futuro. Dirigida "a todo o tipo de trabalhadoras intermitentes (desempregadas, empregados com contratos temporários e a tempo parcial, falsas autónomas, estagiários e qualquer outra pessoa com trabalho precário)", a oficina pretende ser um espaço de coordenação de lutas e resistências para desempregados e precários.
As suas atividades estão organizadas em torno de três eixos. Um deles é a assessoria jurídica gratuita sobre questões laborais, fornecendo informação, respondendo a questões e acompanhando, se for o caso, processos judiciais. Outro é a assessoria para a criação de cooperativas e outras formas de economia social como "alternativa realista ao atual mercado de trabalho". Ambas têm formulários de contacto online. Em terceiro lugar, a Oficina Precaria tem também uma série de campanhas: "a caminho do $10^{\circ}$ de maio", "mulheres e precariedade", "não + bolsas X trabalho" ou "greve sem medo". 
A campanha "no + becas X trabajo", com página online própria, pretende combater o recurso abusivo por parte das empresas a esta figura legal. Para a Oficina Precaria, a difusão dos estágios prolonga a dependência económica dos jovens, favorece a "fuga de cérebros", pressiona para baixo os salários dos trabalhadores com contrato, aumenta o défice da Segurança Social porque os estagiários não se quotizam e as empresas não fazem os descontos, fragmentam os coletivos de trabalho e impedem as formas de representação organizada dos trabalhadores. Com informação legal vasta, a campanha tem no sítio eletrónico um espaço para denúncias, compreende a realização de um estudo rigoroso sobre o fenómeno e passa ainda pela pressão institucional junto do Parlamento e pela mobilização social em conjunto com associações de estudantes. $\mathrm{Na}$ campanha pelo direito à greve, por seu lado, dinamizada em torno da greve geral europeia de 14 de novembro de 2012, estimulava-se os precários impedidos de fazerem greve a juntarem-se aos protestos depois do horário de trabalho e a assinalarem com um laço laranja a pressão de que eram vítimas.

No sítio eletrónico da Oficina Precaria pode ainda encontrar-se informação sobre direitos laborais, sobre as reivindicações do coletivo e sobre matérias como emigração, dívida ou serviços públicos, para além das ações levadas a cabo pelo grupo. Entre elas contam-se debates, participação em manifestações, denúncias, campanhas de rua, flashmobs ou performances políticas, de que é exemplo a "grande passerelle da moda precária", que teatralizou na rua um desfile de moda ironizando sobre as atuais tendências do mercado de trabalho.
Como é sabido, a precarização das relações laborais põe em causa as formas tradicionais de organização dos trabalhadores e isso tem feito emergir em vários países associações e coletivos de precários que procuram reinventar formas de associação, de resistência e de luta. Por outro lado, as grandes mobilizações contra a austeridade e contra o "golpe de estado financeiro" (na expressão dos Indignados espanhóis) nem sempre encontraram formas de continuidade capazes de as inscreverem no tempo. Neste contexto, a Oficina Precaria é uma experiência que merece atenção. Combina temas e referências clássicas do movimento operário (o $1 .^{\circ}$ de maio, o repertório da greve, a defesa dos serviços públicos), campanhas centradas nas novas modalidades precárias de trabalho (como os estágios) e preocupações de ordem mais geral (como a dívida ou a austeridade). Assume a função de prestação de serviços aos trabalhadores precários mas articula-a com a mobilização social e com a luta política pelo reconhecimento dos direitos destes trabalhadores. Luta pela mudança legal e pela alteração da orientação económica dominante mas combina isso com a criação de espaços de produção e de trabalho alternativos à empresa capitalista (como as cooperativas). Desenvolve ação institucional ao mesmo tempo que utiliza formas mais transgressivas de ação, como as performances de rua. Nesta página eletrónica, ativistas e investigadores encontrarão não apenas o registo do que tem sido a atividade deste coletivo, mas também pistas sobre a morfologia do conflito social em contexto de extensão da precariedade a uma parte cada vez mais significativa da juventude e da população em geral.

José Soeiro 